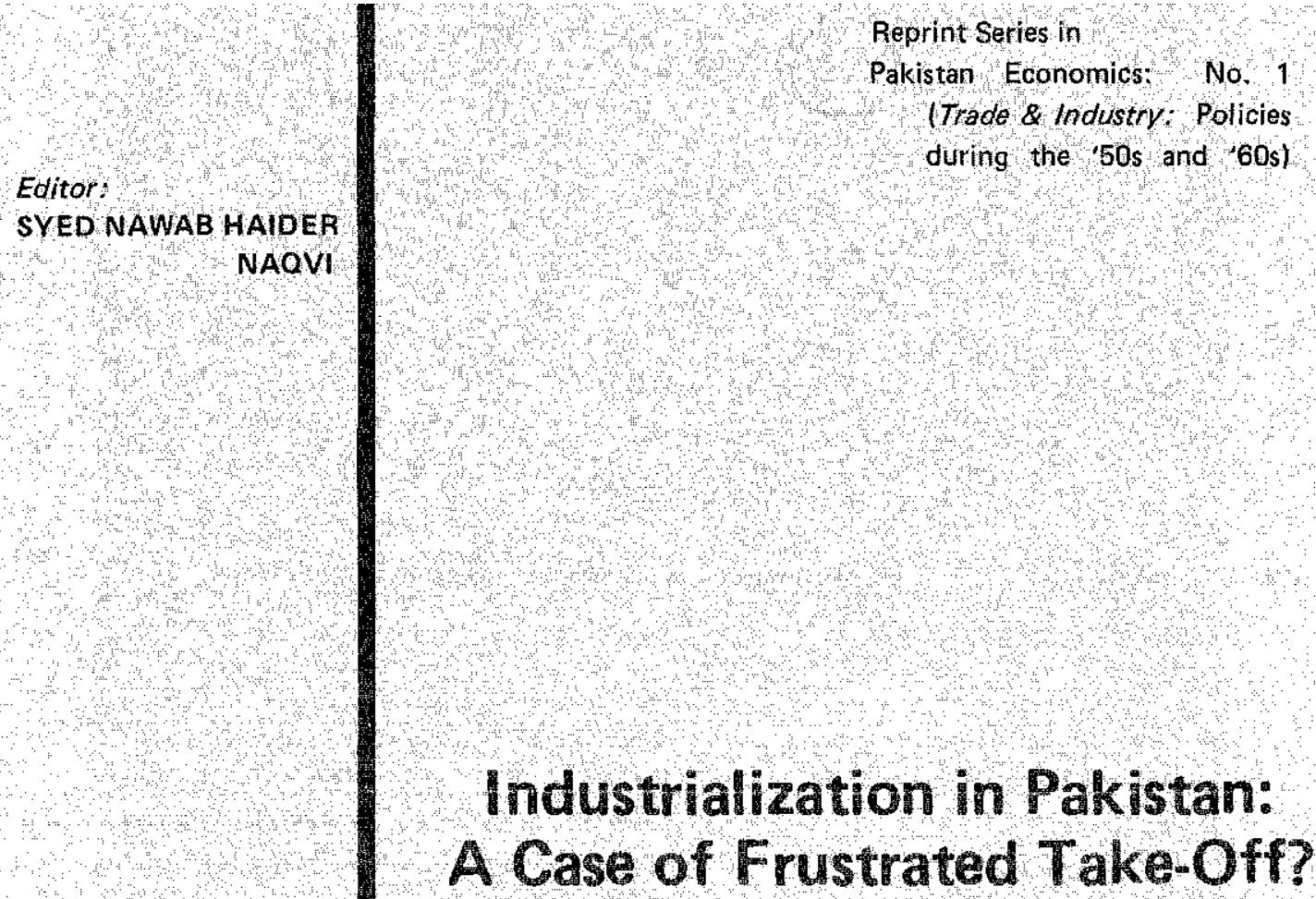

John H. Power

With an introduction by

Syed Nawab Haider Naqui

Pakistan Institute of Development Economics Post Box 1091, Islamabad 


\section{INTRODUCTION}

The first entry in our Reprint Series on Trade and Industry is that of John H. Power's influential paper, which directly stimulated most of the subsequent research on Pakistan's commercial policy. It is being brought out of the limbo of the past not so much to relive 'history' for the fun of it but to enable us to look into the future from the vantage point of the decade of the Fifties, when it all started. The Korean Recession of 1952 was an occasion for the adoption of far-reaching economic policies - in particular, the infinitely complex and incomprehensible economic manoeuvre that the import-licensing system was. Commercial policy was used deliberately to foster economic growth through import substitution. Power's was a dissenting voice when the official version of the success story was the accepted view of Pakistan's economic performance during the Fifties. It is important that the 'story' of that decade be heard now in his own words.

The essence of Power's seminal contribution is a plea to the researchers to go beyond the 'appearances' of official rhetorics promising the imminent dawn of a golden age of economic prosperity, and to evaluate the long-run potential of Pakistan's economy for a "take-off" into self-sustaining growth in terms of the effects of particular policies on balance of trade, savings and the pattern of industrialization. As a result of such an analysis, carried out mostly in an heuristic vein, Power reached his celebrated characterization of Pakistan's growth performance during the Fifties as a case of "frustrated take-off". And this despite a doubling of the percentage share of manufacturing in the national income since 1948-49. The reason for this apparent paradox: economic growth fed by allocative inefficiency, resulting mainly from excessive import substitution of consumer goods, sows the seeds of its own undoing through "consumption liberalization" and an inadequate supply of investible resources, thereby frustrating the economy's potential for a Rostowian take-off. As Power's analysis shows convincingly, this is what did in fact happen in Pakistan during the Fifties: a high rate of growth of large-scale manufacturing was achieved at the cost of a potential improvement in the 
agricultural sector; import substitution was overemphasized at the expense of export expansion; and, finally, the output of consumer goods industries was encouraged without paying due attention to the backward-linkage effects of such a policy on the growth of intermediate goods and capital goods industries. The result of a failure to correct these three types of "structural disequilibria" was that exports and domestic savings stagnated during the Fifties around the "pre-take-off" levels and so did per capita income, with the balance of trade getting ever deeper into the red.

While Power's analysis of the train of events in the Fifties was accurate, as many other studies have also shown, it is interesting to see -- with the benefit of hindsight, of course - how much of it is relevant to an evaluation of Pakistan's subsequent growth performance, and how far his results can be generalized to explain the dynamics of growth in developing countries. Firstly, Power's prognosis about the 'inferior' nature of the import-substitution-led economic growth, engineered mainly by import-licensing plus an overvalued rate of exchange of domestic currency, has now been finally established through the extensive researches done by Jagdish Blagwati and Anne Krueger on "Foreign Trade Regimes and Econonic Develop. ment". There are dissenting voices, but professional opinion now widely recognizes the superiority of export-led growth. Of course, the ideal situation is one in which, on the margin, the marginal cost of earning foreign exchange (export expansion) exactly balances the marginal cost of saving it (import substitution). Yet a policy which errs on the side of the former is less inefficient than the one which is biased in favour of the latter.

Secondly, Power's skepticism about a growth strategy which relies on the exclusive expansion of consumer goods industries through import substitution as an engine of growth sounds plausible although this observation cannot be generalized. After all there are cases - e.g. those of South Korea, Taiwan and Singapore - where such a pattern of industrialization has catapulted the econony onto the path of self-sustained growth. However, in the light of Pakistan's experience Power's analysis was not too much off the mark. He saw this route to a successful take-off as unpromising because market limits are quickly reached once the process of import substitution is completed. Hence deliberate attempts at market expansion, involving an economy-wide rise in real income, the active operation of backward linkages and a rise in exports, will be required to carry the growth-propelling initiatives of such a strategy to fruition. The events of the Sixties have proved that when the economy did achieve high growth and domestic saving rates the achievement involved deliberate steps along the lines suggested by Power. It also required an increasing of the real income through a correction, though only partial, in the pre-existing disequilibrium between agricultural and industrial sectors of the economy by a deliberate policy of turning the terms of trade in favour of the agricultural sector. This was a reversal of the policies of the Fifties which Power had rightly criticised.

Thirdly, the better performance of the Sixties was also associated with a more active operation of backward linkages, from consumer goods industries to 
intermediate goods and capital goods industries. In fact, the latter set of industries grew faster, thereby lowering the share of consumer goods industries substantially during the Sixties below the levels of the Fifties. And many of the importsubstitution industries turned into export industries, thereby decreasing the inefficiency levels in the economy. It is interesting to note that Power strongly doubted if this would happen on the grounds that the then trade policy of Pakistan discriminated against intermediate goods and capital goods industries. This was not entirely correct, because both the domestic policies, like investment licensing, and the import-licensing system, which was a dominant element of trade policy during the Fifties, favoured, rather than discriminated against, the active operation of the backward-linkage effect. Power's mistake was to overplay market mechanism and to ignore the strength of direct controls as allocaters of domestic resources. Furthermore, he mistakenly assumed that the profitability of investment in different industries was solely a function of the relative rates of protection, ignoring completely the fact that domestic competition (even 'among the few') could lower the profitability of consumer goods industries. This is exactly what happened in the case of the textile and the footwear industries where the domestic prices of the final output fell in absolute terms, thereby making protection rates totally redundant as determinants of investment.

Power's analysis also missed two vital links in growth dynamics, which are particularly important now: even if the growth process is not plagued by some of the allocative inefficiencies noted by Power, it will slill be "frustrated" if the techniques of production are not optimally chosen and if high growth rates are secured by a deliberate policy of creating grossly inequitable distributions of income and wealth. In fact, it was the failure to find a satisfactory solution to these problems during the Sixties which explained why even the excellent economic performance of that decade could not pave the way to self-sustaining growth in Pakistan - that is, even when the growth process, by and large, satisfied Power's pre.conditions for a takeoff. Thanks to a failure to make a conscious choice of an appropriate technique in the Fifties and in subsequent years, the capital/output ratio now stands at 3.8:1 - a very high ratio for a capital-poor country like Pakistan. So long as the supply of foreign capital remains highly responsive to domestic needs - as was the case in the Fifties when Power wrote - this does not seem to be much of a problem. However, when this assumption is not satisfied, the growth process will be frustrated, even when efficient by Power's definition, for sheer lack of adequate financing. In fact, the slackening of economic growth during the late Sixties can mostly be explained in terms of a falling net inflow of foreign capital.

Another reason why even the Sixties did not witness the onset of the 'spring' - the decisive leap into "self-sustaining" growth - was the planners' complete indifference to the problems of income distribution as an element of the growth process. The highly fleeting nature of such economic prosperity was highlighted by 
the dramatic events of the late Sixties: widespread industrial strikes and social unrest gave a direct lie to the undue euphoria over the beneficial economic performance of the Sixties. Widely considered to be a model of stability, Pakistan's economic structure turned out to be nothing more than a house of cards before the rising tide of political awareness and 'expectations explosion'. While the high growth rates achieved during that period may have been desirable per se, the resulting pattern of resource allocation deviated sharply from the growth rate which was optimal from the point of view of a socially acceptable distribution of income. However, these points are not so much the defects of Power's analysis as illustrations of the fact that the process of economic growth was not as well understood in the Fifties as it is now. The important thing is that we draw proper lessons from the experience to avoid past mistakes - if only to be able to commit new ones!

Syed Nawab Haider Naqvi Editor 
Reprinted from

The Pakistan Development Review

Vol. III, No. 2 (Summer 1963)

pp. $191-207$

\title{
Industrialization in Pakistan: A Case of Frustrated Take-Off ?
}

\author{
JOHN H. POWER*
}

Development planning in Pakistan aims at reaching the stage of self-generating growth "within a measurable period of time" $[6, \mathrm{p} .4]$. The perspective of long-term growth outlined in the Second Five Year Plan envisages a quadrupling of national income and the achievement of a six-percent per annum growth rate by the end of the Sixth Plan period [6]. This is generally taken to define the period of planned take-off into self-sustained growth. The choice of a 30 -year period is, in any case, consistent with take-off periods identified by Rostow for a number of countries, all of which fall within a range of 20 to 30 years $[10$, p.38]

Whatever merit the device of identifying stages of growth has for economic histroy, the stipulation of a limited period during which it is expected that the transition from economic stagnation to steady progress will have been largely completed has two advantages for development planning. Firstly, in view of the sacrifices required, a landmark of achievement, visible within the time horizon of the "take-off generation", is almost essential if there is to be any measure of popular support for economic development. Secondly, it provides a time schedule of planned progress to discipline policy decisions and to serve as a yardstick against which to measure economic performance.

The first of these functions of an identified take-off period has been largely absent in Pakistan. There has been remarkably little in the way of an attempt to popularize economic development, and correspondingly there has been little in the way of sacrifices asked or made.

As for the second function, the Second Plan targets have been set within the framework of a 30-year perspective and the Planning Commission assesses the economy's progress against the standard of these targets. So, while the 30-year take-off period has not found a place in the popular imagination, it does serve as an operational concept for the planners. How effectively it disciplines policy decisions is another matter, however.

The take-off is a period of acceleration after which steady sustained growth presumably carries the economy to maturity. Therefore, growth in the initial years

${ }^{*}$ Dr. Power is Research Adviser to the [Pakistan] Institute of Development Economics. $\mathrm{He}$ has had the benefit of discussing many questions raised in this paper with advisers and members of the Institute staff, especially Dr. Christoph Beringer, A. R, Khan, and A. H. M. N. Chowdhury. The views expressed are enirely his own, however. 
of the period must be expected to be modest compared to that at the end. Just how modest a growth is consistent with the eventual successful completion of take-off cannot easily be delimited, since there is an infinite variety of time schedules theoretically compatible with ultimate success. Nevertheless, after eight years of "planned development" in Pakistan, it is perhaps appropriate to assess the extent of progress thus far to ascertain whether there are as yet any signs of an incipient launching of take-off. First, however, at the risk of treading all too familiar ground, I will venture a few remarks on the nature of take-off, since in what follows certain aspects of the process will be emphasized at the expense of others.

\section{THE CONCEPT OF TAKE-OFF}

Rostow's preconditions for take-off — an improvement in agricultural productivity to create a surplus for saving, the provision of a minimum of social overhead capital to make investment profitable, and a broad revolution in social attitudes, class structure, and institutions to favour rational calculation and wealth accumulation — are so well known as scarcely to require repeating [10, pp. 17-28]. What must be emphasized, however, is that in the West these preconditions were achieved over centuries of gradual change, while in the newly developing countries today, they must to some extent be created simultaneously with the attempt to launch the take-off itself. This is true even for a country as relatively well favoured in this respect as Pakistan.

This might suggest at the outset that a much longer period of take-off should be contemplated by planners in these countries. There are two important offsetting factors to consider, however. First is the demonstration effect of Western ideas and the material manifestations of Western technology. These aid enormously in hastening the change in attitudes and institutions. Second is the presence of economic aid, This serves to provide the required additional margin of saving plus investment in social overhead capital, thus enabling economic growth to begin earlier and at a higher rate than would otherwise be possible. Under these conditions, the attainment of selfsustaining growth is a process of replacing foreign with domestic saving, as well as one of raising the ratio of investment to income.

Still the presence of foreign aid only raises the possibility of initiating take-off before the preconditions have been fully established. It does not insure that the effort will be successful. Foreign aid can serve to forestall as well as encourage the social and institutional changes that are required. It can serve as an excuse for postponing the reorganization of ownership and production in agriculture that is often a prerequisite to raising agricultural productivity. And, if misdirected, it can fail to provide the infrastructure needed to sustain the growth of directly productive investment. The preconditions cannot be imported, but in their absence what can be imported is rendered less effective.

What this suggests is that one way of assessing progress toward take-off in the Pakistan economy would be to take a careful look at the gains along each of these 
fronts. One suspects that one would find much remaining to be accomplished before the basis for compound-interest growth is laid. And if growth in the first eight years of the 30-year take-off period has been at a pedestrian rate, this may be the most important reason.

But an analysis of the extent to which the preconditions have been established is not the purpose of this paper. I take an agonistic view on the question whether Pakistan can launch a take-off under present conditions. I will address myself rather to less fundamental and more immediate questions about policies affecting saving and investment, especially those which relate to the character of the industrialization process.

So, in turning to Rostow's requirements for the take-off itself, as opposed to the preconditions, I will pass over "the existence or quick emergence of a political, social and institutional framework which exploits the impulses to expansion . . . and gives to growth an on-going character" [10, p.39]. My concern will be instead with his other two requirements: a rise in the rate of investment from five to ten percent of national income, and the development of manufacturing, i.e. industrialization.

In order to provide a theoretical base for what follows, I would like to present a view of the take-off process somewhat different from Rostow's. A part of the difference, though not all of it, stems from the emphasis here on the situation facing the newly developing countries today. I suggest that we focus on three different, but interrelated, structural disequilibria that give the take-off period (for these countries, at least) a specific character.

First is the agriculture-industry sectoral disequilibrium. Given the ratio of land to population almost everywhere in the world, labour productivity in agriculture (with best techniques for given factor proportions) can begin to approach labour productivity in industry only after there has taken place a drastic reallocation of labour (in terms of proportions, if not in absolute terms) away from agriculture and toward industry. This, reinforced by the relative income elasticities of demand for agricultural and industrial products, dictates the basic structural change that is required to raise per capita income and generate a surplus for saving and reinvestment.

Second is the structural disequilibrium at the factor level between the growth of labour supply and saving, Given the rapid rate of population growth in most underdeveloped countries today, it takes a very high rate of saving to equip the additions to the labour force in productive non-agricultural employment. In Pakistan, for example, it has been estimated that in the first two years of the Second Plan only half of the growth of the labour force was able to find non-agricultural employment [7, p.5]. This means simply that a failure to correct the second structural disequilibrium has intensified the first. So a successful take-off requires a sharp rise in the rate of saving. ${ }^{1}$

${ }^{1}$ A sharp fall in the rate of population growth would be a better solution, but this possibility is ignored in the present analysis. 
Third is the disequilibrium between imports and exports. Take-off requires growth rates of the order of five or six percent per annum (given population growth rates of two to three percent). The import requirements of such a growth process would undoubtedly rise even more rapidly in the absence of import substitution. Demand for the traditional primary commodity exports of underdeveloped countries, however, is likely to grow at a much slower rate, while relatively low priceelasticities of demand for these commodities make it undesirable to attempt to increase overall supply at a more rapid rate. This implies a rapidly rising potential balance-of-trade deficit that must be met eventually by import substitution and promotion of new - presumably manufactured - exports, ${ }^{2}$ even if in the short run foreign aid can fill a part of the gap. This need reinforces the urgency of industrialization stemming from the first disequilibrium. On the other hand, a failure on the front of import substitution and export promotion implies also a failure on the saving front, again emphasizing the interrelatedness of these three elements of structural disequilibria. ${ }^{3}$

A substantial rate of progress in the direction of correcting these basic disequilibria is then a part of the general requirements for take-off into self-sustaining growth. To the extent that a country has a relative abundance of high-quality land, adequate water supply, and other natural resources, industrialization is, of course, less urgent, both because of the opportunities for high productivity employment in primary activities and because of the export potential that this implies. Again, if foreign aid could be expected to continue at a rising rate indefinitely, the saving and balance-of-trade problems would be less immediate. For most countries, however - and Pakistan surely falls in the general case - evidence of initiating take-off will include measurable gains along all three fronts.

So, in reviewing the progress of Pakistan's economic development in' the light of the requirements for take-off, the focus will be on industrialization, saving, and the balance of trade. Since a regional breakdown of the data is not yet available, the record relates to the experience of the economy as a whole. Because it is such a critical factor in Pakistan's development, however, I have added a brief comment on the apparent disparity in growth rates between East and West Pakistan.

${ }^{2}$ AS Nurkse points out, the petroleum-exporting countries have proved exceptions to this generalization in recent decades $[4$, pp. 35-45].

${ }^{3}$ The term "structural disequilibria" is used here to suggest something deeper than ordinary "market disequilibria". That is, the solution is not simply one of permitting market forces to exert their natural corrective influences via changes in relative prices. For example, devaluation would not work to correct the third disequilibrium in the absence of some means of reducing the excess of investment over saving. But investment cannot be reduced without giving up the growth goal, and saving is low not because interest rates are low but primarily because the country is poor. Likewise, there is conceptually some set of relative factor prices that could correct the first disequilibrium via inducing a high average labour intensity of production over the economy. But it may be impossible for the market wage rate to fall to the required level, especially if labour in agriculture receives through communal sharing its average product rather than its marginal product. 


\section{INDUSTRIALIZATION AND GROWTH IN PAKISTAN}

Table 1 shows the growth since 1949-50 of national income in aggregate and per capita terms, the change in the shares contributed by agriculture and manufacturing, and the trend of imports and exports. Four facts clearly emerge from these data. Firstly, the past thirteen years have witnessed a significant pace of industrialization. While national income rose by 37 percent, the percentage share contributed by manufacturing doubled, and agriculture's share correspondingly declined.

Secondly, population grew at about the same pace as national income, so that per capita income was virtually unchanged over the period. What slight gain occurred was achieved in the very early years. Annual average per capita income was virtually the same in the three years just prior to the First Plan, during the five years of the First Plan, and in the first three years of the Second Plan.

Thirdly, though the trends of imports and exports are somewhat obscured by the Korean War and erratic fluctuations in the stringency of foreign-exchange licensing, it appears nevertheless that imports have risen substantially while exports have not. On a per capita basis, exports have actually declined. The aggregate data of course hide considerable change in the composition of both exports and imports. Within the latter, there was a great rise in machinery, metals, transport equipment and chemicals; while cotton textile imports declined drastically. On the side of exports, the shift was from raw cotton and jute to their manufactures. Still the rise in manufactured exports was not sufficient to raise total exports significantly, nor was import substitution adequate to raise the share of domestic saving in development expenditure. The result was a rising trend in the dependence on foreign financing.

The fourth fact of importance from Table 1 is, then, the failure of the saving rate to rise. While its behaviour appears erratic, there is no evidence of a rise above the range of five to six percent. The rate of 7.9 percent for 1955-56 was undoubtedly due to the temporary effect of devaluation on tire trade balance; and the rate of 7.4 percent for 1961-62 seems to be equally abnormal for reasons I have discussed elsewhere [8, pp. 131-132]. In any case, with the fall in agricultural production and national income in 1962-63, a drop in the saving rate is likely. The unhappy conclusion is that the saving rate is still at a pre-take-off level.

To sum up, we find over the thirteen years a significant pace of industrialization, some import substitution, but stagnant exports, saving, and per capita income. I turn now to some of the implications of the above findings.

Has industrialization, first of all, contributed to the correction of the first disequilibrium described above - the gap between average labour productivity in agriculture and non-agriculture? Note that our index of industrialization is nonagriculture's share of output, not its share of the labour force. Is the former a good indicator of the latter? 


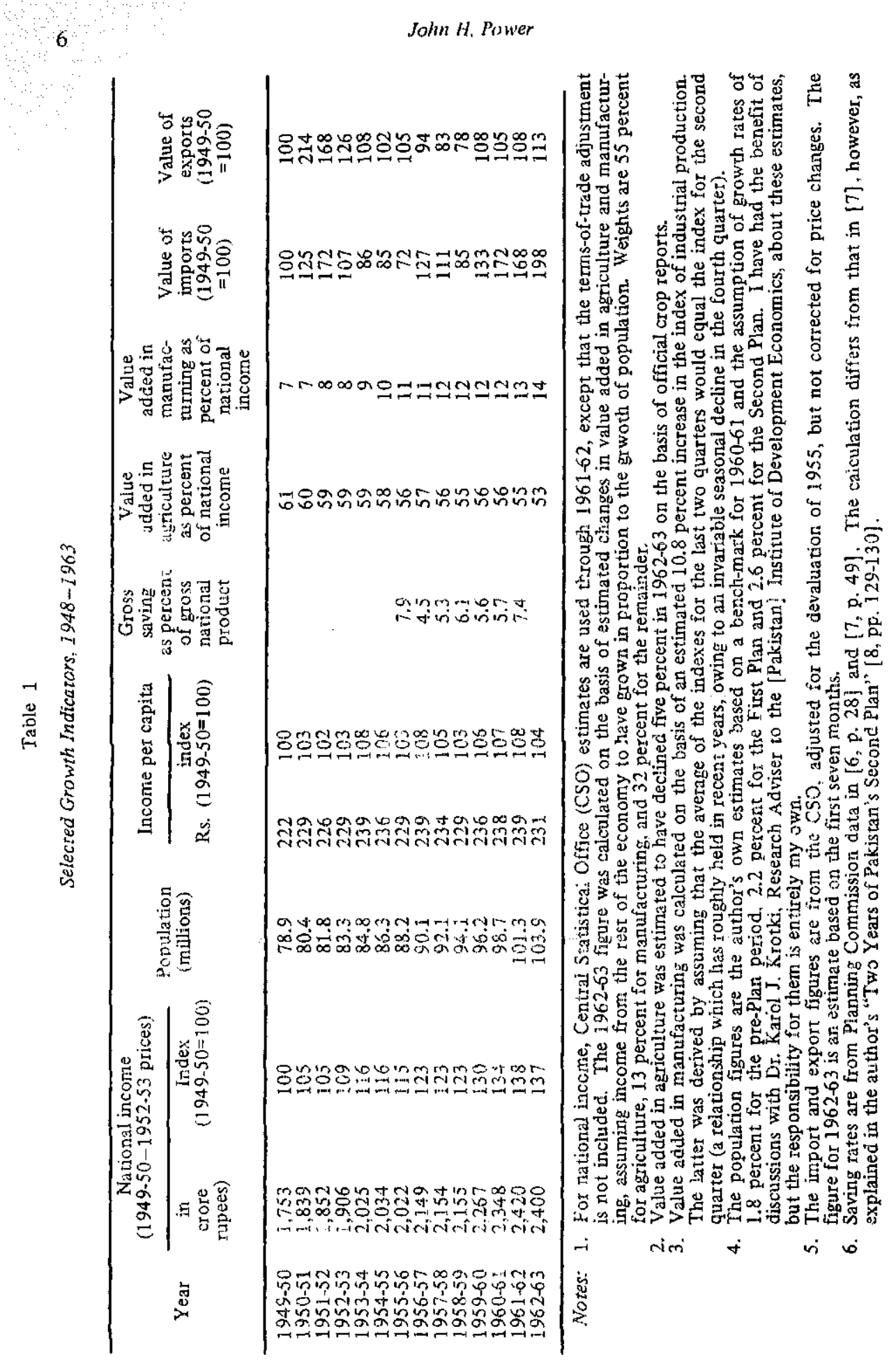


To answer this (and some subsequent questions), consider the identity

$$
\frac{Y_{n}}{Y} \equiv \frac{L_{n}}{L} \cdot \frac{Y_{n} / L_{-n}}{Y / L}
$$

where $Y$ and $L$ are, respectively, national income and total labour force; and $Y_{n}$ and $L_{n}$ are non-agricultural income and non-agricultural labour force. That is, the share of non-agriculture income is the product of the proportion of the labour force in non-agriculture and the ratio of average labour productivity there to average labour productivity in the whole economy.

Assume initially that labour productivity is constant in both agriculture and non-agriculture but that it is higher in non-agriculture. Then a rising $Y / L$ is possible only in association with a rising $L_{n} / L$. In this case $L_{n} / L$ must rise faster than $Y_{n} / Y$ because of the rise in $Y / L$. If, however, we abandon the assumption of constancy and permit productivity in non-agriculture to rise relatively to overall productivity, the rise in $Y_{n} / Y$ can equal or even exceed the rise in $L_{n} / L$. Thus, in the general case nothing can be inferred about the maynitude of the shift in allocation of labour from the change in the sectoral distribution of income.

In the Pakistan case, however, because of the stagnation of per capita income we must add the assumption that $\mathrm{Y} / \mathrm{L}$ is roughly constant (since the labour force as a percentage of the population did not change significantly over the period studied). We can in this case draw a direct inference about productivity in agriculture, as well as the shift in the sectoral allocation of the labour force. For if $Y / L$ is constant, then a rise in $Y_{n} / Y$ implies a rise in the product of $L_{n} / L$ and $Y_{n} / L_{n}$. Ruling out a fall in productivity in non-agriculture as extremely unlikely, ${ }^{4}$ the remaining possibilities all imply a fall in the average productivity of agricultural labour. For otherwise a rise in either or both of these ratios $\left(L_{n} / L\right.$ and $\left.Y_{n} / L_{n}\right)$ would raise $Y / L$. A decline in $L_{n} / L$ coupled with a more than proportionate rise in $Y_{n} / L_{n}$ (however improbable) would also imply a reduction in productivity in agriculture because of the adverse shift in labour allocation. ${ }^{5}$

Moreover, a rise in $L_{n} / L$ is much less likely than a rise in $Y_{n} / L_{n}$ to be associated with a fall in agricultural labour productivity because the labour shift in this case is favourable. The most reasonable inference in the case of constancy of

${ }^{4}$ Since this would have to be accompanied by a rise in $L_{n} / L$ greater than the rise in $Y_{n} / Y$ (which doubled in the period studied), it implies a massive transfer of labour out of agriculture into low-productivity employment or unemployment elsewhere. While it is very doubtful that this has happened, it would not affect the main argument of this paper, since it means simply a transfer from agricultural to non-agricultural underemployment.

5

$$
\frac{Y_{a}}{Y}=\frac{L_{a}}{L} \cdot \frac{Y_{a} / L_{a}}{Y / L} \text { Where the subscript ' } a \text { ' designates the agricultural sector. }
$$

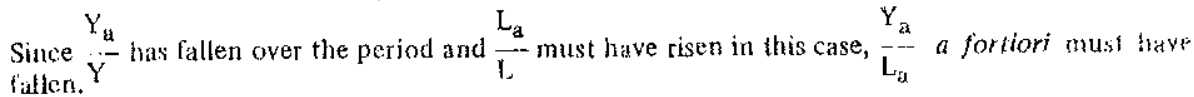


$Y / L$ is, then, that the rise in $Y_{n} / Y$ has been due more to a rise in $Y_{n} / L_{n}$ than to a rise in $\mathrm{L}_{\mathrm{n}} / \mathrm{L}$. This means that the shift in labour allocation has not only failed to match the shift in income proportions, but has failed also to prevent an actual decline in productivity in agriculture. (CSO data indicate a decline of more than 11 percent over the period $1949 / 50$ to $1961 / 62$ ). And only a rise in non-agricultural labour productivity has prevented an economy-wide decline of output per worker. Thus, we can conclude that in Pakistan the rise in the relative share of non-agricultural value added has depended too much on rising productivity in non-agricultural and too little on shifting labour from lower to higher productivity employment to provide any relief from the first disequilibrium.

It could be argued that a given unit of capital invested to raise productivity in this way creates a greater fund for saving and reinvestment, and thus contributes more in the long run to the correction of all three disequilibria. This remains to be proved, however. And in the absence of a clear-cut demonstration of the "economic" superiority of such a strategy, planners would do well to avoid the political and social (dare I say regional?) problems to which it would give rise. In any case, in Pakistan the saving ratio has not risen noticeably with the rise in non-agriculture's share of income, so it is very difficult to justify the sacrifices such a strategy implies. ${ }^{6}$

Turning to the failure of the saving rate to rise, one might be tempted to explain this as a result of the failure of per capita income to rise, but in the analysis of growth dynamics we would be more inclined to explain the latter as a result of the former. In any case even without a rise in per capita income, we might have expected a high marginal saving and reinvestment mechanism to emerge from the rapid increase in the share of income originating in manufacturing. This shift in the distribution of income plays a leading role in many theories of the take-off $[3, \mathrm{pp}$. 233-38]. Why has it failed thus far in Pakistan?

I would like to venture the hypothesis that the character of the industrialization itself, with its emphasis on import substitution - especially the replacement of imported consumption goods - has something to do with it. In so doing I do not mean to downgrade the importance of other explanations any one of a number of which may deserve equal consideration. My reason for focusing on this one is not that I firmly believe it to be more important than any other, but rather that it has been relatively neglected.

I think that it is fair to say that import substitution was not the result of a carefully planned balance-of-payments strategy. Whatever were the reasons for adopting import licensing as the primary control over the foreign-exchange position, I doubt that they included a considered judgement as to the relative merits of various

${ }^{6}$ Substantial improvements in agricultural output can undoubtedly be achieved in Pakistan through better techniques and organization plus relatively inexpensive inputs. This would greatly ameliorate the conditions of the growing redundant farm population and should be given an important place in the development effort. The long-run solution to the problem of poverty in agriculture will, nevertheless, still be dictated by the scarcity of land. 
export-and import-competing industries based on comparative advantage, economies of scale, external economies, marginal saving rates etc.

Nevertheless, the licensing system undoubtedly did influence the direction of industrialization. Since it gave greater protection to finished consumption goods than to intermediate goods or capital equipment, it encouraged investment in the former rather than in the latter. Moreover, since the least essential imports were the most stringently licensed, the system gave a special encouragement to investment in non-essential consumption-goods production.

How strong this influence was, and whether industrialization would have taken this direction anyway, are questions I will not attempt to answer. What matters for what follows is not so much why as the fact that industrialization in Pakistan has been very heavily oriented toward production for domestic consumption, some part of which could hardly be called essential for economic development.

Why should industrialization, oriented toward the production of consumption goods, be less effective in contributing to self-sustaining economic growth than one which emphasizes capital-goods production or production for export? On the surface, the former would seem to have definite advantages. There is an existing market which can easily be reserved for domestic industry by import restrictions. The products are familiar and the marketing system is already established. And there may be fundamental comparative-advantage reasons for developing consumptiongoods industries first.

Moreover, the contribution to saving is potentially just as great for replacement of consumption-goods imports as for replacement of capital-goods imports or promotion of new exports. This can be seen with the aid of another identity:

$$
C_{d}+I_{d}+X_{d} \equiv C_{m}+C_{d}+S
$$

where $C_{d}, I_{d}$ and $X_{d}$ are value added in domestic production, respectively, for consumption, investment, and exports. $\mathrm{S}$ is domestic saving and $\mathrm{C}_{\mathrm{m}}$ is the imported component of consumption. The left-hand side is the national product and the right-hand side is the disposal of national income.

An increase in the national product in the form of a rise in either $I_{d}$ or $X_{d}$ will mean an equal rise in $S$ if consumption $\left(C_{m}+C_{d}\right)$ is not permitted to rise. But a rise in domestic production of consumption goods for domestic absorption will also raise saving to the extent that $\mathrm{C}_{\mathrm{m}}$ is correspondingly reduced. Thus in a case of pure import substitution (the rise in $C_{d}$ being matched exactly by a fall in $C_{m}$ ), $S$ will rise by the increase in national product just as in the case postulated above of a rise in $I_{d}$ or $X_{d}$.

The analysis could be extended to the more general case where consumption is permitted to rise with the rise in national product, but the conclusion is the same. 
The change in saving associated with a rise in output depends on the change in consumption regardless of the kind of goods the output increase embodies. This also emphasizes, however, that if the consumption function is affected by the investment choice, this must be taken into account along with all of the other factors in determining investment strategy.

With this 1 will turn now to what appear to me to be some of the dangers inherent in a strategy of primary emphasis on replacement of imported consumption goods. First, such a strategy must meet Nurkse's balanced-growth requirement [5, pp. 11-17]. There can be no specialization for the home market. This means encouraging investment in the production of a little bit of a lot of things, with all of the disadvantages that this implies. It means in some cases an un-economically small scale of production. In others it means too few firms for the kind of competition that enforces efficiency and progress. It means scattering thinly scarce capital, foreign exchange, and technical and organizational talent. It means, in short, doing many things poorly instead of fewer things well.

As a consequence, the rise in the value added in manufacturing includes a lot of just plain inefficiency in production. Turning the terms of trade against agriculture (by substituling high-priced domestic manufactured goods for cheaper foreign ones) can be justified when a reasonable degree of efficiency turns the high prices into profits for reinvestment. If the high prices are matched by high costs of production, however, the hope of generating self-sustaining growth via such a strategy tends to be frustrated and the rationale for a transfer of saving from agriculture to industry is less evident.

The second danger inherent in this kind of import-substitution strategy is the possibility that the early momentum of industrial development will not be maintained because of a failure to develop a self-generating mechanism of industrial growtl. This is clearly related to the first danger since a profits-saving-reinvestment sequence is a necessary part of any such mechanism. But even if this condition is met, what about the market inducements to invest after the painless take-over of the existing market from foreign competition has been accomplished?

The pace of investment and industrial growth will be gradually slowed as these market limits are reached ${ }^{7}$ unless some combination of three things happens. The first is a rapid growth of productivity across the whole economy (and especially in agriculture) which moves real income per capita ahead fast enough to warrant continuing high investment in industrial growth. The second is the operation of a "backward linkage" effect [1, pp. 100-116] inducing investment in the production of the equipment and intermediate goods used in the consumption-goods industries. That is, import substitution must be extended to the prior stages of production.

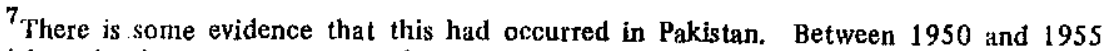
industrial production grew at an annual average rate of 26 percent. In the First Plan period the rate was 11 percent, while in the first three years of the Second Plan, it has been between 9 and 10 percent. 
The third is the opening up of export markets for the surpluses that would develop inevitably if the pace of industrialization is maintained.

Now none of these will happen automatically. There is no natural spontaneous evolution from the kind of "hot-house" industrial growth induced by shutting out imports to this kind of permanent, self-sustaining growth. A rapid rise in productivity is itself inhibited by the implications of the balanced-growth strategy, as discussed above. The same can be said for the development of export markets, with one additional comment. A few markets will even initially be large enough in a country the size of Pakistan to support a number of firms of economical size. These will be for the consumption goods which have a heavy weight in budgets of low-income families, e.g. cotton cloth. While these have great natural advantages for import substitution, they have definite disadyantages for export promotion. The usual low income-elasticity of demand for such goods means that demand in the advanced countries is not growing rapidly. And as the less developed countries nearly unanimously select such industries for early import substitution, the export market is further limited.

This leaves the backward linkage effect on investment to replace imported capital equipment and intermediate goods. What is required is that profits from consumption goods industries be diverted away from rcinvestment there to investment in equipment - and material-supplying industries. This should be a natural development, but there are some influences working against it. Firstly, the capital market is not sufficiently developed to make this kind of reallocation of profits easy. The most likely place for reinvestment of profits is in the industry where they are earned. Nor has the government's taxing and re-lending activities developed sufficiently to fill this gap. Eventually, giant, diversified monopolics of the Japanese Zaibatsu type might substitute for a capital market, but this develop. ment is still at an early stage in Pakistan.

Secondly, since final goods are given greater protection in the import-control system than intermediate and capital goods, investment in the production of the latter always seems less profitable anyway. Ultimately, the growing supply of consumption goods would reduce the profitability of investment there, but this might occur only after the aggregate consumption function has been permitted to rise steadily, defeating all attempts to raise the saving rate.

This brings me to the third danger of such an industrialization strategy -. the danger of consumption liberalization. ${ }^{8}$ We have seen above that replacement by domestic production of imported consumption goods contributes effectively to growth only to the extent that consumption is simultaneously constrained. Unfortunately, however, this strategy carries within it an automatic decontrol of consumption. Let us see how this is so.

We must start with a recognition that some sort of control over consumption was essential right from the beginning of the development effort in Pakistan, everl

${ }^{8}$ For a fuller discussion of this plus empirical evidence for Pakistan. See [2]. 
to achieve a five percent saving rate. The principal instruments of control have been the controls on imports - duties and the licensing system. When most manufactured consumption goods had to be imported, this worked not only to curb imports, but to constrain consumption as well. With substitution of domestic production for imports, however, the proportion of consumption-goods demand so constrained has steadily dwindled with the consequence that consumption has been automatically liberalized.

The objection might be raised that import controls did not really curb consumption effectively, but instead simply diverted it away from imported goods. To a considerable extent this is undoubtedly true, but it is the import substitution itself that made this easy. More important, no doubt, was the shift in income distribution that occurred. As import substitution took place, income was transferred from the government (customs duties) and from the profits of favoured importers to income recipients in the new industries. We can guess that because of the relative inefficiency of these industries, a substantial part of the value added therc became nonprofit income, a much higher proportion of which is consumed. This guess is at least consistent with the empirical evidence cited above.

Finally, we must note the natural tendency for the emergence of pressures to minimize the constraints on consumption when the business community is overwhelmingly committed to the output of consumption goods. As domestic production rose, the constraints on consumption steadily took more the form of restrictions on the licensing of materials, parts and equipment for the consumptiongoods industires, and less the direct limitation of imports of finished goods. And so the phenomenon of excess capacity due to scarcity of imported supplies emerged. While this was clearly the result of a misallocation of investment -- too much capacity installed to produce finished consumption goods and too little to produce materials and equipment - and while to justify the full use of the existing capacity would have required, such a use in consumption as to emasculate the saving plan, all of the pressures were on the side of liberalizing the licensing of supplies. For the excess capacity was there, and the cheapest way to get an increase in production (never mind what kind of production!) was to import supplies. What the economy really needed, of course, was a stiff increase in taxes on consumption to offset the steady erosion of control over consumption, but how can one call for higher consumption taxes when there is excess capacity in the consumption-goods industries? This is the kind of trap into which the industrialization strategy followed by Pakistan (albeit inadvertently) naturally leads.

No doubt there are other important reasons why industrialization in Pakistan has failed to raise the saving rate or even to begin to correct the agriculture/industry disequilibrium. I believe, however, that the foregoing explains a good part of it. Any explanation would be incomplete, however, without at least a brief comment on the question of disparity between East Pakistan and West Pakistan and how this 
relates to what has been said. This is undertaken in the next section which is then followed by a brief conclusion.

\section{EAST-WEST DISPARITY}

Unfortunately we do not yet have national income data broken down for the two provinces. Consequently, we cannot simply read off the various growth indicators and compare them. So what I propose to do instead is to fit the East-West relationship into an ordinary simple growth model in order to see what might be implied by the few bits and pieces of information we do have.

Consider the case of an overwhelmingly agricultural economy in which population is growing rapidly, land is very scarce, average labour productivity in agriculture is lower than in not-agriculture and marginal labour productivity in agriculture is considerably below average (perhaps even zero), so that a rapid shift in labour allocation away fron agriculture is essential to prevent a decline in per capita income there. This is, I think, one way of describing Fast Pakistan. While industrialization, if successful, will eventually alter the dependence on agriculture, the success of industrialization itself depends in the first instance on the existence of a surplus in agriculture and the appropriation of a part of that surplus for investment in industry.

The appropriation may take place in a variety of ways, but for the present analysis I would like to focus on just two. Assume that a significant part of agricultural output is exported. Assume further that the nation's currency is overvalued and that industrialization is being encouraged behind the protection of import duties or import licensing or both. It might be said that under these circumstances agriculture is being exploited to the benefit of industry. For the foreign exchange it earns in exports cannot be used to buy inexpensive manufactured goods in world markets, but instead must be converted into home currency to buy the expensive products of protected domestic industry.

This would be quite misleading, however, for the alternative to developing (even inefficient) domestic industries is to permit the growing labour force to pile up in agriculture, steadily reducing average living conditions there. The appropriation should be thought of rather as a means by which the agricultural population equips (perhaps involuntarily) its surplus for employment elsewhere in its own interest. Note, however, in line with the analysis set out earlier, that the industrial development could be so inefficient that it fails to generate an industrial take-off via a rising saving rate.

The other means of transfer of saving from agriculture is simply a balanceof-trade surplus with non-agriculture and the rest of the world combined. That is, to the extent that agriculture does not use its foreign-exchange earnings to buy from non-agriculture (assuming that it is prohibited from buying in world markets), there is a capital outflow which can be appropriated by non-agriculture to run a 
deficit with the rest of the world. Again, however, this could (though it need not) be the means of improving agriculture via industrialization.

Suppose, however, that the transfer occurs without the accompanying movement of labour into non-agricultural employment. In this casc the saving transfer does not have the rationale suggested above, and it is difficult to find any justification for it. Yet it is something like this that has happened in East Pakistan.

Over 14 years, from 1948 to 1961, East Pakistan's total balance-of-trade surplus was about Rs. 1,500 million, a capital outflow which, together with foreign capital of about Rs. 3,900 million, financed West Pakistan's cumulative deficit of Rs. 5,400 million. ${ }^{9}$ In addition, East Pakistan had a deficit of about Rs. 3,500 million with West. If we assume that on the average Pakistan products are priced 40 percent above their equivalents in world markets, there is implied and additional transfer from East Pakistan to West Pakistan of about Rs. 1,000 million. This gives a total transfer of about Rs. 2,500 million for 14 years, or about Rs. 180 million per year. This is more than two percent of East Pakistan's average annual income for the period as best we can estimate it. In addition, if we assume that East Pakistan's share of the foreign capital inflow into West Pakistan was in proportion to its population, the transfer would be almost doubled.

What would we expect the result to be of a transfer of this magnitude, unmatched by any significant labour migration? Unless East Pakistan had an enormous saving capacity, we would expect lagging industrial development, rapidly rising unemployment, and possibly a decline in per capita income. And while it is difficult to document this result, unofficial estimates seem to confirm it.

Again, it is possible to justify the temporary worsening of the position of a particular region (as well as of a particular sector) if this results in such substantial gains elsewhere that a reverse transfer can occur at an early date. It would be nothing less than a tragedy, however, if the result is no better than stagnation for the whole economy.

\section{CONCLUSIONS}

My conclusions can be summarized very briefly:

i. The doubling of the percentage share contributed by manufacturing to national income since $1948-49$ represents an impressive rate of industrialization, taking the form principally of replacement of imported consumption goods. It has not resulted so far, however, in any appreciable progress in the direction of correcting the three disequilibria defined above. There is as yet no sign of an incipient take-off in Pakistan.

ii. To achieve a pace of industrialization that will propel the whole economy toward self-sustaining growth requires, first of all, a rise in the saving rate.

${ }^{9}$ Sources for the data in this paragraph are the CSO and [9]. I an indebted to A. R. Khan for compiling the data. 
This has not yet occurred. Moreover, it requires the extension of import substitution to intermediate and capital-goods production, or the rapid expansion of exports, or both. These will not occur automatically and, in fact, are inhibited by present tax and exchange-rate policies.

iii. Per capita income has not risen significantly and agricultural per capita income has probably fallen. Moreover, it has undoubtedly fallen most in East Pakistan. A strategy of industrialization which, in the short run, leads to a deterioration in living conditions in the agricultural sector and in the East Pakistan region could be justified only if the acceleration of industrial progress were so great that the industrial sector would in the near future begin to absorb the whole of the increase in the labour force plus a portion of the rural underemployed. This seems out of sight, however, in the light of recent experience.

iv. This means, I think, that far more attention should be given to measures that will provide for an early improvement in agricultural productivity. Substantial increases of per acre yields of agricultural output ate possible with relatively inexpensive additional inputs. These would ameliorate the situation in agriculture even if they would do nothing to correct unemployment. In addition, however, a much larger rural public works programme must be rapidly implemented - especially in East Pakistan. Without substantial increases in agricultural production, any attempt to accelerate industrialization is likely to be frustrated by shortages of food and raw materials. In any case, however, living conditions in East Pakistan agriculture cannot improve significantly (in the absence of large-scale emigration) until a far greater proportion of industrial investment is allocated to that province.

v. At the same time, steps must be taken to encourage rapid expansion of exports and production of intermediate and capital goods. The system of overvaluation of the currency plus licensing plus exports bonus scheme discriminates against both. Foreign exchange is valued more highly in substituting for imports of final consumption goods than in producing equipment and supplies or goods for export. Until this is corrected, little progress can be expected on this front.

vi. Finally, talk of reducing dependence on foreign aid would appear to be premature. Until economic growth has attained real momentum, Pakistan must continue to rely heavily on external financing of its develpment effort. There is no great virtue in self-financed stagnation. What is required to make aid effective, however, is a much more strenuous effort to mobilize domestic resources for development. A rapidly rising rate of domestic saving would eventually bring dependence on foreign aid to a natural end. This, in turn, implies sacrificing consumption gains for a considerable time to come. The above analysis suggests that, in any case, what gains in income have occurred have been limited to a small urban minority. It is the propensity to consume of this small minority that must, first of all, be curbed via tax or other measures. This is strong medicine, but the alternative might be continuing stagnation with rising external indebtedness. 


\section{REFERENCES}

1. Hirschman, A. O. The Strategy of Economic Development. New Haven: Yale University Press. 1958.

2. Khan, A. R. "Import Substitution, Export Expansion and Consumption Liberalization: A Preliminary Report". Pakistan Development Review. Vol. IIl, No. 2. Summer 1963.

3. Lewis, W. A. The Theory of Economic Growth. Homewood, Illinois: Richard D. Irwin, Inc. 1955.

4. Nurkse, R. Patterns of Trade and Development. Stockholm: Almquist and Wiksell. 1959.

5. Nurkse, R. Problems of Capital Formation in Underdeveloped Countries. New York: Oxford Uriversity Press, 1960.

6. Pakistan. Planning Commission. Second Five Year Plan. Karachi. June 1960.

7. Pakistan. Planning Commission. Mid.Plan Review of Progress in 1960-61 1961-62 under the Second Five Year Plan. Karachi. March 1963.

8. Power, I. H. "Two Years of Pakistan's Second Plan”. Pakistan Development Review. Vol. III, No. 1. Spring 1963.

9. Rahman, M. A. Partition, Integration, Economic Growth, and Inter-regional Trade. Karachi: [Pakistan] Institute of Development Economics. 1963.

10. Rostow, W. W. The Stages of Economic Growth. Cambridge: Cambridge University Press. 1960. 
This work is licensed under a

Creative Commons

Attribution - Noncommercial - NoDerivs 3.0 Licence.

To view a copy of the licence please see:

http://creativecommons.org/licenses/by-nc-nd/3.0/ 